\title{
Modern aspects on Shigella pathogenecity and vaccine development - A Review
}

\author{
Partha Pal \\ Department of Zoology, Scottish Church College, \\ 1 \& 3 Urquhart Square, Kolkata - 700006, India \\ Phone: 91-33-2350-3862 \\ E-mail address: parthapal_iicb@yahoo.co.in
}

\begin{abstract}
Shigella species are intracytosolic Gram-negative invasive enteropathogenic bacteria, causing the rupture, invasion and inflammatory destruction of the human colonic epithelium. They utilize the host cytoskeletal components to form propulsive actin tails. The so-called invasive phenotype of Shigella is linked to expression of a type III secretory system (TTSS) injecting effector proteins into the epithelial cell membrane and cytoplasm, thereby inducing local but massive changes in the cell cytoskeleton that lead to bacterial internalization into non-phagocytic intestinal epithelial cells. The molecular and cellular bases of this invasive phenotype essentially encompass crossing of the epithelial lining, apoptotic killing of macrophages, entry into epithelial cells, and escape into the cytoplasm, followed by cell-to-cell spread. Intracellular colonization is likely to protect the microorganisms from killing by humoral and cellular effectors of the innate immune response. Concurrently, the capacity of Shigella to reprogram invaded epithelial cells to produce proinflammatory mediators plays a major role in the strong inflammatory profile of the disease. This profile is likely to impact on the nature and quality of the adaptive response, which is dominated by humoral protection at the mucosal level. In recent years, a large amount of information has been generated regarding the host, pathogen and environmental factors that impact the pathogenesis of shigellosis at the cellular and molecular level. This review summarizes what is currently known about Shigella, detailing those factors that contribute to pathogenesis and examining the current progress in the development of a vaccine.
\end{abstract}

Keywords: Shigella; Enteropathogen; TTS-System; Pathogenesis; Vaccine

\section{INTRODUCTION}

Species of the genus Shigella are among the bacterial pathogens most frequently isolated from patients with diarrhea. Five to fifteen percent of all diarrheal episodes worldwide can be attributed to an infection with Shigella, including 1.1 million fatal cases (Kotloff et al., 1999). Two-thirds of all episodes and deaths occur in children under 5 years. The emergence of multidrug-resistant Shigella strains and a continuous high disease incidence imply that shigellosis is an unsolved global health problem (Sansonetti, 2006). Shigellosis is an acute intestinal infection, the symptoms of which can range from mild watery diarrhea to severe inflammatory bacillary dysentery characterized by strong abdominal cramps, fever, and stools containing blood and mucus. A combination of oral 
rehydration and antibiotics leads to the rapid resolution of infection. Currently, there is no protective Shigella vaccine available, but several vaccines using bacterial components or killed or live-attenuated bacteria for immunization are under development and are being tested in different clinical phases (WHO, 2006). Here, we cover recent progress in our understanding of the evolution of Shigella virulence, current concepts on the mode of pathogenesis on cellular and molecular level, and the recent status on the development of vaccine against the disease.

\section{EVOLUTION OF SHIGELLA VIRULENCE}

Shigella spp. are gram-negative, nonsporulating, rod-shaped bacteria that belong to the family Enterobacteriaceae. The first report on the isolation and characterization of bacteria causing bacillary dysentery, later named Shigella, was published by Kiyoshi Shiga at the end of the 19th century (Shiga, 1897). Descriptions of numerous differing strains followed over the next decades, with all of them being closely related to the nonpathogenic bacterium Escherichia coli. To distinguish the pathogenic strains of high clinical relevance from lesspathogenic or nonpathogenic strains, the genus Shigella was defined based on biochemical, serological, and clinical phenotypes (Ewing, 1949). The genus Shigella includes the four species $S$. dysenteriae (serogroup A), S. flexneri (serogroup B), S. boydii (serogroup C), and $S$. sonnei (serogroup D). According to variations in their $\mathrm{O}$ antigens, the species were further divided into several serotypes. S. flexneri and, to a lesser extent, $S$. sonnei are endemic and cause the majority of all infections (Kotloff, 1999). S. dysenteriae accounts for epidemic disease outbreaks and the most severe form of dysentery, which causes the majority of fatal shigellosis cases.

Comparative genomics have challenged the traditional serological classification recently. Several studies using different technical approaches clearly prove that Shigella spp. belong to the species E. coli, rather than forming a separate genus (Fukushima et al., 2002; Ochman et al., 1983; Pupo et al., 1997; Rolland et al., 1998). Moreover, diarrheagenic enteroinvasive E. coli (EIEC) strains share biochemical characteristics, essential virulence factors, and clinical symptoms with Shigella spp. While EIEC does not completely fulfill the definition of the genus Shigella, genome analysis revealed a closer relationship to Shigella spp. than to commensal E. coli strains (Lan et al., 2004; Yang et al., 2007).

Comparative genomics clearly indicates that Shigella spp. and EIEC evolved from multiple E. coli strains by convergent evolution (Pupo et al., 2000; Yang et al., 2007). Phylogenetic studies of Shigella deduced either from numerical and phenotypic taxonomy or from comparative genomics showed three main Shigella clusters, each containing strains from the traditionally defined species, are identified. S. sonnei and some $S$. dysenteriae strains are more distantly related to these main clusters but still group with $E$. coli. The three main Shigella clusters started to diverge from E. coli 35,000 to 270,000 years ago (Lan and Reeves, 2002). S. sonnei is of more recent origin and separated from the other strains about 10,000 years ago (Shepherd et al., 2000). Since EIEC retained more characteristics of commensal E. coli than Shigella spp., these strains apparently acquired the virulence machinery more recently and might reflect an earlier stage of the evolutionary process undergone by Shigella spp. (Lan et al., 2004; Yang et al., 2005).

In addition to a reassignment of the phylogenetic relationships between Shigella strains, comparative genomics provides insight into the genetic basis of Shigella virulence. The genetic information constituting the phenotypes of Shigella spp. is encoded on the bacterial 
chromosome and on a large virulence plasmid. The virulence plasmid is an essential virulence determinant of all Shigella spp. and encodes the molecular machinery necessary for tissue invasion and the intracellular lifestyle (Sansonetti et al., 1983; Sansonetti et al., 1982; Sasakawa et al., 1986). The central element of this machinery is a TTS-system. The TTSsystem enables the bacteria to translocate a set of approximately 25 proteins from the bacterial cytoplasm directly into the eukaryotic host cell, where these "effector" proteins interfere with various host cell processes (Ogawa and Sasakawa, 2006; Parsot, 2005; Tran Van Nhieu et al., 2005).

The complete sequences of the virulence plasmids and chromosomes of several Shigella strains including all four species are currently available (Buchrieser et al., 2000; Jiang et al., 2005; Jin et al., 2002; Nie et al., 2006; Venkatesan et al., 2001; Wei et al., 2003; Yang et al., 2005). Furthermore, the genomes of a strain collection representing all serotypes of Shigella were characterized by comparative genomic hybridization (Peng et al., 2006). This vast amount of genetic information allows the identification of the successive genetic events that led to the evolution of pathogenic Shigella from nonpathogenic E. coli and provides insight into how variations in the virulence traits of different Shigella strains developed.

\section{PATHOGENESIS OF SHIGELLA INFECTION}

Shigella spp. are transmitted by the fecal-oral route and enter the human body via the ingestion of contaminated food or water. They are highly infectious, since as few as 10 to 100 microorganisms are sufficient to cause disease (Dupont et al., 1989). Furthermore, it was shown that Shigella spp. are able to down regulate the expression of antimicrobial peptides, which are important antibacterial effectors constantly released from the mucosal surfaces of the intestinal tract (Islam et al., 2001). After passage through the stomach and small intestine, the bacteria reach the large intestine, where they establish an infection. Shigella entry into cells is affected by a type three secretion system, which is a needle-like apparatus that injects effector proteins directly into the host cell cytoplasm to modulate host cell functions. Delivery of early effector proteins induce rearrangements of actin cytoskeleton resulting in membrane remodelling and bacteria uptake, which is followed shortly by bacterial escape from the vacuole (Clerc and Sansonetti, 1987; Menard et al., 1994). Intracellular Shigella triggers the polymerization of polymerized host actin and leads to dissemination of Shigella in the intestinal epithelium (Goldberg, 2001). For efficient actin tail formation, the Shigella outer membrane protein IcsA, the host actin nucleation-promoting factor N-WASP, and Toca-1 are required (Lommel et al., 2001; Snapper et al., 2001; Egile et al., 1999; Suzuki et al., 1998; Leung et al., 2008). N-WASP is maintained in an auto-inhibited state in the resting cells (Ho et al., 2004; Bompard and Caron, 2004). Toca-1 activates N-WASP by relieving NWASP auto-inhibition during Shigella actin tail formation. The recruitment of Toca-1 to bacteria is dependant on type three secretion system (Bompard and Caron, 2004) but the protein responsible for the recruitment process is not yet known.

A key step in Shigella pathogenesis is the ability of this intracellular pathogen to mediate its own uptake of into normally non-phagocytic epithelial cells. Several type 3 secreted effectors including IpgB1 are involved in this process. IpgB1 is GEF (GTP exchange factor) (Huang et al., 2009) that localizes to host cell membranes at bacterial entry sites where it activates the small GTPase Rac and Cdc42 to induce membrane ruffling which promote the uptake of Shigella into host cells (Hachani et al., 2008; Alto et al., 2006; Handa 
et al., 2007; Ohya et al., 2005). Shigella strains that no longer encode IpgB1 are impaired in invasion are attenuated in virulence (Ohya et al., 2005). The translocation of IpgB1 into host cells is dependent on Spa15, a class IB type 3 secretion chaperone (Page et al., 2002). In addition to IpgB1, Spa 15 binds to and mediates the secretion of eight additional Shigella effectors (Page et al., 2002; Niebuhr et al., 2000; Ogawa et al., 2003; Schmitz et al., 2009). Interestingly, these nine effectors share a conserved amino acid sequence, the conserved chaperone binding domain (CCBD) sequence, within their first 50 residues that mediates interactions with Spa 15 (Costa et al., 2012).

The most frequently linked with endemic outbreaks of shigellosis are caused by $S$. flexneri strains. They invade the colonic and rectal epithelium of their host and cause severe tissue damage. Recent findings elucidated the contribution of the periplasmic enzyme, Lasparaginase (AnsB) to the pathogenesis of $S$. flexneri. The bacterial OmpA, is a prominent outer membrane protein whose activity has been found to be required for bacterial pathogenesis, and is reported to be up-regulated in ans $B$ mutant cells. Overexpression of OmpA in wild type $S$. flexneri serotype $3 \mathrm{~b}$ resulted in decreasing the adherence of this virulent strain, suggesting that the up-regulation of OmpA in ans $B$ mutants contributes to the reduced adherence of this mutant strain (George et al., 2014).

\section{CURRENT APPROACHES FOR DEVELOPMENT OF SHIGELLA VACCINE}

The diversity of the worldwide Shigella serotype isolates and their variable relative importance in developing versus developed countries led to the conclusion that a multivalent Shigella vaccine will have to be developed to address the needs of the different potential target populations for an efficacious Shigella vaccine. It is expected that a vaccine which will include $S$. dysenteriae type 1, S. sonnei, S. flexneri 2a, S. flexneri 3, and S. flexneri 6 will cover more than $75 \%$ of the global Shigella-associated episodes of diarrhea (Levine et al., 2007). The Shigella vaccine development strategies of the last 50 years and the current ones include the two main distinct categories of live-attenuated vaccine strains and inactivated Shigella vaccine candidates (subunit and whole cell).

\section{1. Live-attenuated Shigella strains}

Mel and colleagues demonstrated the efficacy of the SmD vaccines, showed that multiple strains could be mixed together in combination vaccines and reported that protection was serotype specific. Protection persisted for a year following primary immunization of children, but administration of a single booster extended the protection for an additional year (Mel et al., 1971; 1974).

A similar live-attenuated Shigella vaccine (S. flexneri 2a strain T32) was developed in Romania by repeated subculturing (Meitert et al., 1984). The field trials also suggested that T32 conferred significant protection against shigellosis due to $S$. sonnei, S. flexneri $1 \mathrm{~b}$ and $S$. boydii 1-6. Later, it was shown that T32 harbored a large deletion in the invasiveness plasmid, resulting in the loss of three loci, ipaADCB, invA, and virG, which diminished the ability of this strain to invade epithelial cells (Venkatesan et al., 1991).

Advances in recombinant DNA technology and more recently whole genome sequencing of shigellae enabled the development of live-attenuated oral Shigella candidates with defined deletion mutations, knocking out virulence genes on the invasiveness plasmid that encode for intracellular spread and altering key metabolic pathways, impairing synthesis of nucleic acids, impairing the capacity to compete for ferric iron, via the production of 
siderophores (i.e. aerobactin). A second generation of more attenuated $S$. sonnei mutants, WRSs2 and WRSs3, were constructed at WRAIR (Barnoy et al., 2011; Bedford et al., 2011). A combination of these gene deletions with the addition of the knockout of the chromosomal set locus encoding for the ShET1 were applied for $S$. flexneri 2 a candidate vaccine strains WRSf2G11, WRSf2G12, and WRSf2G15 (Ranallo et al., 2012).

\section{2. Inactivated Shigella vaccine candidate}

In the early attempts to develop a vaccine, inactivated, whole-cell preparations of Shigella were developed and administered parenterally (Levine et al., 2007).

LPS-based vaccines were developed in concert with case control and prospective studies demonstrating an association between serum LPS IgG antibodies and serotypespecific protection against shigellosis (Cohen et al., 1991; Passwell et al., 1995).

Investigators at the National Institutes of Health developed parenterally administered conjugate Shigella vaccines by covalently binding the serotype-specific polysaccharides of Shigella to a carrier protein, thus obtaining T-cell-dependent antigens, immune memory, and a better immune response. They were found as very safe, with minimal systemic adverse and local adverse events (Ashkenazi et al., 1999; Passwell et al., 2003).

The efficacy of these conjugates was examined where a randomized, double-blind efficacy study was done in 1-4-year-old children at 15 sites throughout Israel (Passwell et al., 2010). The study demonstrated that the $S$. sonnei conjugate had a protective efficacy of $71 \%$ in 3-4 year-old children, but not in younger ones (Passwell et al., 2010).

With the idea of developing a multivalent subunit Shigella vaccine, candidate vaccines based on the type three secretion system, which is utilized by all shigellae, were developed. IpaB- and IpaD-based Shigella vaccines, with adjuvants, given to mice intranasally (Martinez-Becerra et al., 2012), parenterally (Martinez-Becerra et al., 2013), or orally (Heine et al., 2013), were promising, shown as immunogenic and protective against lethal pulmonary infection with Shigella.

\section{DISCUSSION AND CONCLUSION}

More than 100 years after their discovery, Shigella spp. still poses a worldwide major health problem due to the devastating diarrhea that the bacteria may cause. Research performed over the last 25 years has tremendously contributed to our understanding of shigellosis on molecular, cellular, and organismic levels. Thus, we gained profound insight into the evolution of Shigella spp. originating from harmless enterobacterial relatives, the structure and function of the major virulence factors, including a TTS-System and their cognate effectors which are multi-domain proteins optimized not only to be recognized as bacterial secreted substrates, but also to act within eukaryotic host cells (Costa and Lesser, 2014). An in-depth understanding of the molecular mechanisms underlying the mode of pathogenesis is a prerequisite to design a protective, live-attenuated Shigella vaccine strain that is safe and efficient. In concert with ongoing efforts to improve hygiene standards, such a vaccine would offer substantial relief from what is still one of the most dreadful bacterial pathogens.

In the present review, it was concluded that current researches are focussing on the diverse innovative approaches based on progress in molecular technology, elucidation of the virulence mechanisms in understanding the molecular basis of pathogenesis of Shigella and development of a licensed safe and efficacious Shigella vaccine to protect humans against 
this pathogen and the related morbidity and mortality. This present review will also help for further research in understanding the evolutionary mechanisms of new Shigella isolates having epidemic potential, the mode of pathogenesis of virulent strains and the development of a suitable vaccine strain for this bacterial pathogen.

\section{Acknowledgement}

The author conveys his gratitude to Dr. Rupak K. Bhadra, Senior Principal Scientist, Infectious Diseases and Immunology Division CSIR- Indian Institute of Chemical Biology Jadavpur, for providing the necessary literatures, planning for doing this review paper.

\section{References}

[1] Alto N.M., Shao F., Lazar C.S., Brost R.L., Chua G., Matto S., McMahon S.A., Ghosh P., Hughes T.R., Boone C., Dixon J.E., Cell 124 (2006) 133-145.

[2] Ashkenazi S., Passwell J.H, Harlev E., Miron D., Dagan R., Ramon R., Farzam N., Majadly F., Bryla D.A., Karpas A.B., Robbins J.B., Schneerson R., J Infect Dis 179 (1999) 1565-1568.

[3] Barnoy S., Baqar S., Kaminski R.W., Collins T., Nemelka K., Hale T.L., Ranallo R.T., Venkatesan M.M., Vaccine 29 (2011) 6371-6378.

[4] Bedford L., Fonseka S., Boren T., Ranallo R.T, Suvarnapunya A.E, Lee J.E., Barnoy S., venkatesan M.M., Gut Microbes 2 (2011) 244-251.

[5] Bompard G., Caron E., J Cell Biol 166 (2004) 957-962.

[6] Buchrieser C., Glaser P., Rusniok C., Nedjari H., D’Hauteville H., Kunst F., Sansonetti P., Parsot C., Mol Microbiol 38 (2000) 760-771.

[7] Clerc P., Sansonetti P.J., Infect Immun. 55 (1987) 2681-2688.

[8] Cohen D., Green M., Block C., Slepon R., Ofek I., J Clin Microbiol 29 (1991) 386-389.

[9] Costa S.C., Schmitz A.M., Jahufar F.F., Boyd J.D., Cho M.Y., Glicksman M.A., Lesser C.F., M Bio 3 (2012) e00243-00211.

[10] DuPont H.L., Levine M.M., Hornick R.B., Formal S.B., J Infect Dis 159 (1989) 1126-1128.

[11] Egile C., Loisel T.P., Laurent V. Li R., Pantaloni D., Sansonetti P.J., Carlier M.F., J Cell Biol 146 (1999) 1319-1332.

[12] Ewing W.H., J Bacteriol 57 (1949) 633-638.

[13] Fukushima M., Kakinuma K., Kawaguchi R., J Clin Microbiol 40 (2002) 2779-2785.

[14] George D.T., Mathesius U., Behm C.A., Verma N.K., PLoS ONE 9(4) (2014) e94954.

[15] Goldberg M.B., Microbiol Mol Biol Rev 65 (2001) 595-626.

[16] Hachani A., Biskri L., Rossi G., Marty A., Menard R., Sansonetti P.J., Parsot C., Van Nhieu G.T., Bernardini M.L., Allaoui A., Microbes Infect 10 (2008) 260-268. 
[17] Handa Y., Suzuki M., Ohya K., Iwai H., Ishijima N., Koleske A.J., Fukui Y., Sasakawa C., Nat Cell Biol 9 (2007) 121-128.

[18] Heine S.J., Diaz-McNair J., Martinez-Becerra F.J., Choudhari S.P., Clements J.D., Picking W.L., Pasetti M.F., Vaccine 31 (2013) 2919-2929.

[19] Ho H.Y., Rohatgi R., Lebensohn A.M., Le Ma., Li J., Gygi S.P., Kirschner M.W., Cell 118 (2004) 203-216.

[20] Huang Z., Sutton S.E., Wallenfang A.J., Orchard R.C., Wu X., Feng Y., Chai J., Alto N.M., Nat Struct Mol Biol 16 (2009) 853-860.

[21] Islam D., Bandholtz L., Nilsson J., Wigzell H., Christensson B., Agerberth B., Gudmundsson G., Nat Med 7 (2001) 180-185.

[22] Jiang Y. et al., Plasmid 54 (2005) 149-159.

[23] Jin Q. et al., Nucleic Acids Res 30 (2002) 4432-4441.

[24] Kotloff K.L., Winikoff J.P., Ivanoff B., Clemens J.D., Swerdlow D.L., Sansonetti P.J., Adak G.K., Levine M.M., Bull WHO 77 (1999) 651-666.

[25] Lan R., Alles M.C., Donohoe K., Martinez M.B., Reeves P.R., Infect Immun. 72 (2004) 5080-5088.

[26] Lan R., Reeves P.R., Microbes Infect 4 (2002) 1125-1132.

[27] Levine M.M., Kotloff K.L., Barry E.M., Pasetti M.F., Sztein M.B, Nat Rev Microbiol 5 (2007) 540-553.

[28] Leung Y., Ally S., Goldberg M.B., Cell Host Microbe 3 (2008) 39-47.

[29] Lommel S., Benesch S., Rottner K., Franz T., Wehland J., Kuhn R., EMBO Rep 2 (2001) 850-857.

[30] Martinez-Becerra F.J. et al., Infect Immun 80 (2012) 1222-1231.

[31] Martinez-Becerra F.J., Scobey M., Harrison K., Choudhari S.P., Quick A.M., Joshi S.B., Middauqh C.R., Picking W.L., Vaccine 31 (2013) 2667-2672.

[32] Meitert T., Pencu E., Ciudin L., Tonciu M., Arch Roum Pathol Exp Microbiol 43 (1984) 251-278.

[33] Mel D.M., Arsic B.L., Radovanovic M.L., Litvinjenko S.A., Acta Microbiol Acad Sci Hung 21 (1974) 109-114.

[34] Mel D., Gangarosa E.J., Radovanovic M.L., Arsic B.L., Litvinjenko S., Bull World Health Org 45 (1971) 457-464.

[35] Menard R., Sansonetti P., Parsot C., EMBO J 13 (1994) 5293-5302.

[36] Nie H. et al., BMC Genomics 7 (2006) 173.

[37] Niebuhr K., Jouihri N., Allaoui A., Gounon P., Sansonetti P.J., Parsot C., Mol Microbiol 38 (2000) 8-19.

[38] Ochman H., Whittam T., Caugant D.A., Selander R.K., J Gen Microbiol 129 (1983) 2715-2726.

[39] Ohya K., Handa Y., Ogawa M., Suzuki M., Sasakawa C., J Biol Chem 280 (2005) 24022-24034. 
[40] Ogawa M., Sasakawa C., Cell Microbiol 8 (2006) 177-184.

[41] Ogawa M., Susuki T., Tatsuno I., Abe H., Sasakawa C., Mol Microbiol 48 (2003) 913-931.

[42] Page A.L., Sansonetti P., Parsot C., Mol Microbiol 43 (2002) 1533-1542.

[43] Parsot C., FEMS Microbiol Lett 252 (2005) 11-18.

[44] Passwell J.H., Ashkenazi S., Banet-Levi Y., Ramon R., Farzan N., Lerner-Geva L., Vaccine 28 (2010) 231-235.

[45] Passwell J.H. et al., Pediatr Infect Dis J 22 (2003) 701-706.

[46] Passwell J.H., Freier S., Shor R., Farzan N., Block C., Lison M., Shiff E., Ashkenazi S., Pediatr Infect Dis J 14 (1995) 859-865.

[47] Peng J., Zhang X., Yang J., Wang J., Yang E., Bin W., Wei C., Sun M., Jin Q., BMC Genomics 7 (2006) 218.

[48] Pupo G.M., Karaolis D.K., Lan R., Reeves P.R., Infect Immun 65 (1997) 2685-2692.

[49] Pupo G.M., Lan R., Reeves P.R., Proc Natl Acad Sci USA 97 (2000) 10567-10572.

[50] Ranallo R.T., Fonseka S., Boren T.L., Bedford L.A., Kaminski R.W., Thakkar S., Venkatesan M.M., Vaccine 30 (2012) 5159-5171.

[51] Rolland K., Lambert-Zechovsky N., Picard B., Denamur E., Microbiology 144 (1998) 2667-2672.

[52] Sansonetti P.J., PloS Med 3 (2006) e354.

[53] Sansonetti P.J., Hale T.L., Dammin G.J., Kapfer C., Collins H.H., Formal S.B., Infect Immun 39 (1983) 1392-1402.

[54] Sansonetti P.J., Kopecko D.J., Formal S.B., Infect Immun. 35 (1982) 852-860.

[55] Sasakawa C., Kamata K., Sakai T., Murayama S.Y., Makino S., Yoshikawa M., Infect Immun 54 (1986) 470-475.

[56] Schmitz A.M., Morrison M., Agunwamba A.O., Nibert M.L., Lesser C.F., Nat Methods 6 (2009) 500-502.

[57] Shepherd J., Wang G.L., Reeves P.R., Infect Immun. 68 (2000) 6056-6061.

[58] Shiga K., Saikingaku Zasshi 25 (1897) 790-810.

[59] Snaper S.B. et al., Nat Cell Biol 3 (2001) 897-904.

[60] Suzuki T., Miki H., Takenawa T., Sasakawa C., EMBOJ 17 (1998) 2767-2776.

[61] Tran Van Nhieu G., Enninga J., Sansonetti P., Grompone G., Curr Opin Microbiol 8 (2005) 16-20.

[62] Venkatesan M.M., Fernandez-Prada C., Buysse J.M., Formal S.B., Hale T.L., Vaccine 9 (1991) 358-363.

[63] Venkatesan M.M., Goldberg M.B., Rose D.J., Grotbeck E.J., Burland V., Blattner F.R., Infect Immun 69 (2001) 3271-3285.

[64] Wei J. et al., Infect Immun. 71 (2003) 2775-2786. 
[65] WHO (2006) Geneva, Switzerland

http://www.who.int/topics/global_burden_of_disease/en/

[66] Yang F. et al., Nucleic Acids Res 33 (2005) 6445-6458.

[67] Yang J., Nie H., Chen L., Zhang X., Yang F., Xu X., Zhu Y., Yu J., Jin Q., J Mol Evol 64 (2007) 71-79. 